\title{
El Dr. Manuel Justo Domínguez Quintanar, fundador de la puericultura racional y la pediatría técnica en México
}

\author{
Manuel A. Baeza-Bacab
}

Facultad de Medicina, Universidad Autónoma de Yucatán; Academia Nacional de Medicina de México (Pediatría); Academia Mexicana de Cirugía (Pediatría); Academia Mexicana de Pediatría, Mérida, Yucatán, México

\begin{abstract}
Resumen
Se presentan algunos aspectos biográficos, personales y profesionales, del Dr. Manuel Justo Domínguez Quintanar, natural de la ciudad de Querétaro, quien a lo largo de 80 años vivió de cerca las épocas históricas que conformaron a México como país independiente: desde la primera república federal hasta el porfiriato, participando muy activamente en todas ellas, ya sea como médico, profesor, administrador o político. Destacó por su trabajo en las instituciones de beneficencia, principalmente en la Casa de Niños Expósitos (La Cuna), por lo que fue considerado años después el fundador de la puericultura racional y el creador de la pediatría técnica en México.
\end{abstract}

PALABRAS CLAVE: Pediatría. Historia. Niños. Puericultura.

\begin{abstract}
This paper presents some biographical notes, both personal and professional, for Dr. Manuel Justo Dominguez Quintanar; a native of Queretaro, who over 80 years lived firsthand the historical stages in which Mexico turned into an independent country: from the First Federal Republic to the Porfiriato. He had an active participation in them all; either as a doctor, a teacher, administrator or politician. He was renowned for his charity work, especially in the Foundling House (The Cradle), which made him years later, to be considered as the founder of rational childcare and the creator of technical pediatrics in Mexico.
\end{abstract}

KEY WORDS: Pediatrics. History. Children. Childcare.

\section{Introducción}

De acuerdo con el Dr. Alfonso G. Alarcón, en México, como en otros países, la puericultura ha sido hija de la obstetricia y la pediatría hija de la puericultura; por tanto, los primeros puericultores y pediatras fueron los parteros, a quienes la presencia del recién nacido los obligaba a ser los protectores de la infancia sana y, necesariamente, médicos del niño enfermo'. Sin embargo, afirma el Dr. Alarcón, no se puede negar que en México haya existido puericultura antes de la era genuinamente científica del arte médico. Ahí está la Casa de Niños Expósitos (La Cuna), fundada por Don Antonio Lorenzana y Buitrón, arzobispo de México, a finales del siglo XVIII, que aunque fue creada sin experiencia ni cultura especial, siempre mostró preocupación por conservar la alimentación humana en los lactantes. Sin embargo, el fundador de la puericultura racional fue el Dr. Manuel Domínguez, quien en 1884, hace poco más de 130 años, consagró su atención y los servicios de La Cuna exclusivamente a los lactantes ${ }^{1}$. El presente trabajo relata algunos aspectos de la vida personal y profesional del

\section{Correspondencia:}

Gac Med Mex. 2017;153:928-937

Contents available at PubMed www.gacetamedicademexico.com 
Dr. Manuel J. Domínguez Quintanar, médico, político, administrador y maestro, pero sobre todo benefactor de la niñez mexicana.

\section{Los orígenes del Dr. Manuel J. Domínguez Quintanar}

Nació en la ciudad de Querétaro el 6 de agosto de 1830. Sus padres fueron el general Juan B. Domínguez y la señora María Ignacia Quintanar Delgado. Fue bautizado en la Parroquia de Santa Ana por el presbítero Manuel Borja González, dándole los nombres de Manuel Justo, siendo su padrino el vicegobernador del Estado de Querétaro, don Nicolás Berasaluce. Sus primeros años los pasó en San Juan del Río, Querétaro, donde su madre tenía unas haciendas. Al iniciar su educación fue enviado a Querétaro y confiado a la tutela del Padre Borja. A los 7 años fue inscrito en una escuelita, situada en la calle de la Verónica, dirigida por las señoras Bustillos, donde la enseñanza incluía el uso del «puntero» y el «Silabario de San Miguel». La instrucción primaria la cursó bajo la dirección del virtuoso profesor Agustín Guevara, teniendo como compañero a Manuel Carmona y Valle. Ahí, según comenta el Dr. Domínguez, aprendieron bastante bien lectura, escritura, el Catecismo del $\mathrm{Pa}$ dre Ripalda y las reglas fundamentales de la aritmética $^{2,3}$. Fue en ese entonces cuando se inició una estrecha amistad con Carmona y Valle, que duró toda la vida. Así lo recuerda Manuel Domínguez, en 1909, en el discurso que pronunció con motivo de un homenaje póstumo a su amigo: «He procurado, señores, formar de mis añoranzas un burdo canevá en que bosquejo la vida del que para mí fue casi un hermano. En nuestra querida escuela de primeras letras, alguna vez fui mirado por la generalidad de los niños con repulsión, con burlas o con miedo, porque la epidermis se me desprendía en amplias placas a causa de una escarlatina que había padecido. Ninguno de mis pequeños camaradas quería ocupar asiento inmediato al mío, y en las horas de recreo era eliminado de los juegos, quedando aislado en un rincón del patio, desde donde miraba con llorosos ojos a mis crueles compañeritos, entregados a las expansiones jubilosas de la edad feliz. Uno, sin embargo, Manuel Carmona, tenía la abnegación suficiente para acercarse a mí, venciendo la natural repugnancia que debía causarle, y me hablaba con cariñoso interés y solía obsequiarme sus muñequitos de barro para que con ellos atemperase mi negra melancolía» ${ }^{4}$.

\section{Los estudios de medicina en la ciudad de México}

A los 12 años de edad, el joven Domínguez viajó a la capital a continuar sus estudios, ingresando al Colegio de San Juan de Letrán, primero con el carácter de becario y después como alumno externo. Era rector del establecimiento el Dr. José M. ${ }^{a}$ Iturralde, y bajo su dirección estudió dos años de latinidad con el Lic. Asiain, el primer año de filosofía con el Lic. Calleja y el segundo con el Lic. Miguel C. Alatriste, el valiente caudillo de la democracia, que muchos años después fue fusilado cerca de Puebla ${ }^{2,3}$.

En ese entonces, y de conformidad con el decreto del Plan General de Estudios propuesto por el presidente López de Santa Anna el 18 de agosto de 1843, los estudios preparatorios para la carrera de medicina duraban 6 años, pudiendo realizar los primeros 4 años en alguno de los colegios de la capital (San Gregorio, San Hipólito o San Juan de Letrán), donde los llevó a cabo el Dr. Domínguez. Después de ese período, en 1847, se inscribió como alumno de la Escuela de Medicina, que ese año se había trasladado al Colegio de San Juan de Letrán, donde cursó los últimos 2 años de estudios preparatorios, que incluían física y química médica, impartidos por los venerables sabios Ladislao de la Pascua y Leopoldo Río de la Loza, respectivamente. Ese año falleció su padre y tuvo que continuar sus estudios atenido a sus propios recursos ${ }^{3,5-7}$.

En ese entonces, el director de la escuela era el Dr. José Ignacio Durán, y de acuerdo con el decreto mencionado, el programa de estudios de la carrera duraba 5 años y vale la pena resaltar que en el quinto año se incluía el curso Obstetricia, enfermedades de mujeres paridas y niños recién nacidos, lo que muestra un interés temprano por la salud infantil ${ }^{8}$. En 1849 se cambió al antiguo Hospital de San Hipólito, donde se cursaban los estudios prácticos de medicina. El Dr. Domínguez recordaba con tristeza que, en ese entonces, la administración del general Santa Anna convirtió al Hospital de San Hipólito en cuartel para su ejército, dejando a los estudiantes sin un lugar donde realizar sus estudios de medicina. «Protestamos en masa, alumnos y maestros en contra del titánico despojo; sin embargo, la justicia veló su divino semblante y anduvimos, como los parias de Brahma, de un lugar a otro, rechazados en todas partes, y sin más abrigo para la continuación de nuestras tareas escolares que las casas de nuestros catedráticos. Concluyó la crisis con la compra que hicieron 
nuestros abnegados maestros del edificio del Tribunal del Santo Oficio de la Inquisición, que fue en un tiempo antro de tenebrosas inquisiciones y que hoy es nido de luz intelectual, y bajo la venerable techumbre de este edificio tocamos la meta de nuestra carrera» ${ }^{4}$. Después de haber sido practicante del Hospital de San Andrés, presentó su examen de Medicina, Cirujía y Obstetricia el 19 de diciembre de 1854, habiendo sido aprobado por unanimidad de votos por el jurado calificador, integrado por los profesores Ignacio Herazo, José Espejo, Manuel Robredo, Ignacio Torres y Anastasio Peñuñuri. Provisto de su título se dirigió a la ciudad de León, Guanajuato, pero no encontró trabajo y al cabo de algunos días se trasladó a San Juan del Río, residencia habitual de su madre, casada ya en segundas nupcias con un hombre de genio y talento, el Dr. José G. Perusquía. El dulce calor materno, las manifestaciones amistosas de gran parte del vecindario, el clima y los recuerdos de la infancia lo enraizaron en aquel suelo. Así sucedió, y aún, cuando más tarde su padre político resolvió fijar su residencia en la metrópoli, él continuó bajo aquel cielo absorbiendo la clientela del lugar, y como sucede ordinariamente en todas las poblaciones pequeñas, su permanencia y su trabajo impulsaron al vecindario a solicitar al gobernador del Estado que lo nombrara prefecto de distrito en $1859^{5,6,10}$.

\section{Un médico liberal entre imperialistas}

Acontecimientos políticos lo obligaron a emigrar a la capital, donde permaneció hasta la instalación del gobierno imperial de Maximiliano. Partidario del nuevo orden de cosas políticas, fue nombrado prefecto del distrito de San Juan del Río, por lo que el 15 de agosto de 1864 le correspondió recibir al emperador Maximiliano en su viaje rumbo a Querétaro. El prefecto Domínguez declaró el día como fiesta nacional, hizo liberar a los presos de condenas leves y organizó diversas celebraciones por tan fausto acontecimiento; incluso, al venir Maximiliano sin Carlota, la pareja del emperador en el baile de honor fue Paz Domínguez, hermana del prefecto. En ese entonces se describe al Dr. Domínguez como un joven médico, quien se había pasado del partido liberal al del imperio, siendo muy popular a causa de sus ideas humanitarias ${ }^{8}$. En ese encargo fue muy útil a los vecinos de la ciudad, pues logró normalizar la marcha de los servicios públicos, restaurar el orden y garantizar los intereses de la comunidad, servicios que reconoció el gobierno imperial premiándolo con la condecoración de
Caballero de la Orden Imperial de Guadalupe el 16 de agosto de $1864^{\circ}$. El 10 de febrero de 1866 se unió en matrimonio con la señorita Adelaida Girón Rico en San Juan del Río, teniendo en esa época el dolor de perder a su madre. En su matrimonio tuvo siete hijos, dos de los cuales murieron muy pequeños. Sin embargo, los datos del archivo de San Juan del Río solo mencionan a seis: Manuel Ignacio, Salvador, Gustavo, Felipe, Adelaida y Octavio 2,3,7.

Al paso de apenas 3 años, desorganizado su gobierno, Maximiliano volvió a pasar por el hermoso San Juan del Río rumbo a Querétaro, en un viaje del cual ya no retornaría. Tuvo el Dr. Domínguez que seguir la suerte de su jefe, incorporándose con él en su camino a la ciudad de Querétaro, a la cual entraron el 19 de febrero de 1867. Poco después llegaron las fuerzas republicanas que establecieron el famoso sitio de Querétaro, que concluyó con la ocupación de la plaza y el fusilamiento del emperador Maximiliano. En los primeros días del memorable sitio se presentaron en el alojamiento del Dr. Domínguez los generales Leonardo Márquez y Tomás Mejía para solicitarle, en representación del emperador, que aceptase el delicado cuanto peligroso cargo de prefecto imperial de Querétaro. El compromiso fue tal, que aceptó y al final del drama cayó prisionero con los demás vencidos. No obstante su posición oficial, durante el sitio tuvo el coraje y la audacia de desafiar calladamente a los imperialistas, manifestó su sensibilidad humana, tuvo acciones solidarias en favor de la población, hizo que sus carencias fueran menos dolorosas, les facilitó alimentos y protegió a los liberales prisioneros, evitándoles castigos y venganzas. Por lo anterior, las personas de valer de la ciudad, muy especialmente las afiliadas al partido liberal triunfante, en recompensa por los varios servicios que les había prestado intercedieron a favor del Dr. Domínguez con el general en jefe Mariano Escobedo, quien accedió y ordenó que el prisionero fuese puesto en libertad, sin más compromiso que el de ir a hacer entrega del archivo de la prefectura de San Juan del Río a la persona que se había designado para ese cargo. Al día siguiente salió para cumplir la orden recibida, lo cual fue posible gracias a la generosidad del Dr. Vicente Licea, ginecólogo queretano, quien le facilitó una onza de oro en calidad de préstamo amistoso. A los pocos días de estar en San Juan, sus amigos de Querétaro le enviaron un aviso de que había llegado de San Luis Potosí la orden de que fuesen pasados por las armas Maximiliano, los generales Márquez y Mejía, un señor Pasos pagador de las fuerzas y el prefecto 
Domínguez; diciendo, además, que no fuera a cometer el quijotismo de presentarse, porque no podrían responder del resultado, y como él no había empeñado su palabra de acudir en ulteriores emergencias, abandonó la ciudad y anduvo, poco más de 2 meses, disfrazado de ranchero hasta que pudo entrar a la metrópoli ocupada ya por el Sr. Juárez y su gobierno, ocultándose en la casa de la familia Riba y Echeverría $23,7,10$.

\section{Sus inicios como médico en la república restaurada}

No transcurrió mucho tiempo para que el señor don Antonio Riba presentase a su oculto amigo ante el señor ministro Sebastián Lerdo de Tejada, quien no lo envió a la prisión improvisada para los presos políticos en La Enseñanza, sino que le dio la ciudad por cárcel durante 2 años. En esas condiciones, hizo venir de San Juan del Río a su esposa y al único hijo que por entonces tenían, y se establecieron en una humilde casa en la calle de la Santísima, situada hacia el oriente del zócalo y detrás del Palacio Municipal, esperando que los productos de la profesión bastasen para cubrir los gastos del modesto hogar. Sin embargo, los escasos clientes que acudían a la consulta eran pobres y no producían lo suficiente, obligando a los cónyuges a una nueva separación: la familia se regresó a San Juan del Río y el Dr. Domínguez se alojó en un cuarto de los baños de Betlemitas que le fue cedido por su buen amigo don Ruperto Barrera, gerente de la negociación, quien además le formó el núcleo de una clientela, consiguiendo que algunos de sus amigos formasen una «iguala» en la que por una cantidad mensual tuviesen derecho a los servicios médicos que les prestaría el Dr. Domínguez ${ }^{2,3}$.

En 1870 consiguió el puesto de prefecto de estudios en la Escuela Nacional de Medicina, que estaba dotado con $\$ 500.00$ anuales, lo que permitió que los esposos se reunieran de nuevo. Cabe señalar que en ese entonces la escuela ya estaba ubicada en el antiguo Palacio de la Inquisición, y que en los corredores del segundo patio se encontraba el internado. Ahí conoció al poeta Manuel Acuña, entonces estudiante de medicina, con quien cultivó una fraternal amistad que se refleja en el soneto que Acuña escribió a su maestro:

A mi querido amigo y maestro Manuel Domínguez ${ }^{11}$

Sabiendo, como sé, que en esta vida

Todo es Ilanto, tristeza y amargura,

$Y$ que no hay ni siquiera una criatura
Que no lamente una ilusión perdida.

Sabiendo que la dicha apetecida

Es la sombra y no más de una impostura,

Y que la sola aspiración segura

Es la que al sueño eterno nos convida:

Mi voz no puede levantar su acento

Para desearte, a más de los que tienes,

Otros años de lucha y sufrimiento;

Pero mi voz te da sus parabienes,

Porque sé que hasta el último momento

Brillará la honradez sobre tus sienes.

Pero, la mejor prueba del singular afecto que el poeta tenía para su maestro fue la postrera carta que le dejó al Dr. Domínguez antes de quitarse la vida en el internado de la Escuela Nacional de Medicina, en la cual le confiaba dos misiones penosas: primero, le hacía saber que el veneno que había ingerido era cianuro de potasio para que no se hiciera la autopsia a su cadáver: "haga usted que no despedacen mi cuerpo», le pidió con insinuante frase; y segundo, le suplica que le disculpe ante el director de la escuela, Dr. Rafael Lucio, por haber tomado esa determinación en el establecimiento ${ }^{12}$. Su historia como prefecto termina en 1877 cuando renunció al empleo.

Regresando a 1870, debemos mencionar que en ese año se abrió un concurso de oposición para profesor de medicina legal. Participaron en el concurso los Dres. Agustín Andrade y Manuel Domínguez, quien presentó la tesis El alcoholismo: su historia, causas, efectos patológicos, sociales, su terapéutica y recursos legales para evitar el vicio. Ambos fueron aprobados en la primera votación, pero en la segunda el Dr. Andrade obtuvo la mayoría de votos y el derecho a desempeñar la cátedra. Esto no desalentó al Dr. Domínguez y al año siguiente, en 1871, se presentó al concurso abierto para proveer de catedrático adjunto a la clase de terapéutica, ya que el Dr. Manuel Robredo había solicitado licencia para separarse del puesto por estar seriamente enfermo. Obtuvo la clase habiendo presentado la tesis Haba del calabar, comenzando a funcionar en enero de 1872. Tres años después, el 22 de febrero de 1875, falleció el Dr. Robredo, recibiendo entonces por parte del gobierno del señor Lerdo de Tejada el título de profesor propietario de dicha asignatura. Ese mismo año, el gobierno del Distrito Federal lo nombró propagador de la vacuna en la ciudad y sus alrededores. En marzo de 1877 obtuvo por oposición la plaza de médico sifilógrafo en el Hospital de San Andrés. Asistió como delegado por nuestro país al Congreso Médico reunido en Roma en 1894, y en noviembre de 1902 se encargó de la 
Dirección de la Escuela de Medicina por ausencia del Dr. Eduardo Liceaga $3,13,14$.

\section{Actividades políticas y servidor público durante el porfiriato}

Su participación en el gobierno imperialista de Maximiliano no impidió al Dr. Domínguez ocupar diversos puestos de elección popular durante el porfiriato, ya que fue regidor, gobernador, diputado y senador de la república. En su primera actividad política en ese período, el Dr. Domínguez participó, y aparentemente triunfó, en las elecciones de 1878 para diputado por el tercer distrito de Querétaro; sin embargo, en una carta pública dirigida a sus electores señaló un presunto fraude para favorecer al Lic. Hilarión Frías. En dicho documento expresa su gratitud y confianza al pueblo de San Juan del Río por haberlo designado de manera espontánea y unánime su representante en el $9 .^{\circ}$ Congreso Constitucional ${ }^{15}$. No fue diputado en esa legislatura, pero ese mismo año, 1878, fue electo regidor del Distrito Federal, cargo que ocupó en varias ocasiones $(1879,1880,1885$, 1886 y 1893), siendo presidente del ayuntamiento en 1880 y en 1893; además, en este último año ocupó el cargo de gobernador del Distrito Federal en sustitución del general José Ceballos, quien había fallecido. También fue diputado en la decimoséptima y decimoctava legislaturas del Congreso de la Unión, senador suplente por el Distrito Federal en 1886 y senador por el Estado de Zacatecas para el período de 1906 a $1910^{2,3,14}$.

\section{Agrupaciones y sociedades médicas}

Fue miembro del Liceo Hidalgo, la Sociedad Mexicana de Geografía y Estadística, la Sociedad Católica de México y la Sociedad de Historia Natural; presidente de la Sociedad Filoiátrica y de Beneficencia de los alumnos de la Escuela de Medicina; la Sociedad Médica de Guanajuato; socio honorario del Gran Círculo de Obreros y de la Sociedad Dental Mexicana; socio correspondiente de la Sociedad Médico-Farmacéutica de Yucatán; colaborador de la Sociedad Médica de Guadalajara; y socio honorario y presidente de la Academia Nacional de Medicina en 1886. En particular se debe señalar que, a instancias del Dr. Domínguez, se creó el 12 de mayo de 1867 la Sociedad Médica Hebdomadaria, una agrupación científica, de beneficencia y recreativa que reunió a sus compañeros los Dres. Francisco Brasseti, Manuel Carmona,
José María Bandera, Eduardo Licéaga y Juan María Rodríguez, con el objeto de formar un grupo de hermanos que se consultaran las dificultades que en su profesión les ocurrieran, se proporcionaran periódicamente unos a otros en sus casas distracción y solaz, y se ayudaran en las adversidades de la vida; posteriormente la agrupación cambió su nombre a Sociedad Familiar de Medicina, 3,12,16.

\section{Su participación en la Academia Nacional de Medicina}

El Dr. Manuel Domínguez ingresó a la Academia Nacional de Medicina el 13 de mayo de 1868, fue reconocido como socio honorario el 7 de marzo de 1885, y poco después fue electo presidente de la corporación para el período 1886-1887. Escribió varios trabajos en Gaceta Médica de México, por ejemplo «Memoria sobre la inocuidad de la vacuna humana», «Fiebre puerperal», «Prescripciones magistrales», «Breves reflexiones acerca del modo de recetar en México", «Tuberculosis, autopsia de un sujeto muerto de esa enfermedad», "Reflexiones sobre un error de diagnóstico en caso de embarazo», «El jaborandi», «De la apomorfina», «Del colorín», «Algunas reflexiones sobre la acción fisiológica de la eserina», «Breves reflexiones sobre la administración terapéutica del oxígeno», «Estrechamientos uretrales», «Peritonitis», “Uretrotomía» y «Del tártaro»"17. Sin embargo, tal vez su participación más conocida sea la defensa que realizó en el seno de la Academia sobre la inocuidad y la seguridad de la vacuna, la cual el propio Dr. Domínguez describe de la siguiente manera: «Se agitaba en la Academia Nacional de Medicina en el año de 1868 una importante discusión referente a la vacuna, a la que se llamó degenerada por vieja, a la que se acusaba de que con ella y por ella, si llevaba sangre del vacunífero, penetraba o podía penetrar el repugnante virus sifilítico al limpio organismo de los niños; siendo forzoso, por ende, abandonarla, substituirla con la linfa de terneras vacunadas. Acusación tan injusta alarmó al público, y la Academia quedó erigida en Gran Jurado para juzgar al reo. Sostenían la acusación, principalmente, los Dres. Iglesias y Carmona, siendo sus defensores los igualmente titulados Andrade, Rodríguez y Reyes. Por mi parte, aun sintiéndome pequeño frente a los combatientes en la liza científica, me creí obligado a alzar la voz en defensa del inestimable tesoro puesto por Dios en nuestras manos contra la asoladora viruela. Obré así, porque, habiendo sido vacunador oficial durante varios años, 
figuraban en los apuntes que conservo más de 20,000 vacunados por mi mano, siempre con éxito; aun cuando a veces tomaba con la lanceta linfa sanguinolenta, sostuve que no son los glóbulos rojos de la sangre vectores de la sífilis accidentalmente tomados al herir el botón vacunal; ofreciéndome en comprobación de mi aserto a sufrir en mi persona la inoculación de sangre de un sifilítico. Aceptado el ofrecimiento, se me reconoció debidamente hasta la persuasión de que en mi organismo no había vestigios de pasada infección sifilítica ni venérea; y en determinado día fui llevado a la garita de San Lázaro, de la que era empleado un individuo sifilítico en segundo período, que se prestó al experimento. De la piel de dicha persona, y por los territorios libres de la erupción pústulo-crustácea, que casi la cubría, se tomó sangre con la lanceta, que luego se me transmitió con la misma, hasta por ocho punciones en los brazos; siendo de ver entonces el empeño de Carmona en que el instrumento estuviese bien cargado del líquido que se me transmitía. Se informó a la Academia del resultado del experimento, que, para mi fortuna, fue completamente negativo ${ }^{4}$.

Otra anécdota importante relacionada con esta discusión la relata el Dr. Luis Hidalgo y Carpio, editor de Gaceta Médica de México en una nota editorial que precede a la publicación del discurso titulado "¿La vacuna humana puede ser vehículo de la sífilis?", pronunciado el 2 de septiembre de 1868 por el Dr. Domínguez ante la Sociedad Médica de México (denominación previa de la Academia), en la cual podemos leer lo siguiente: «El discurso no fue publicado inicialmente en la Gaceta porque la sección de la Academia, encargada de la redacción, creyó conveniente abstenerse por entonces de darlo a luz, ya que ese examen ponía de manifiesto la ligereza con que L'Académie Impériale de Médecine de París aceptó los hechos de la sífilis vaccinal, que Mr. Depaul adujo como prueba de su existencia. Según hemos leído en varias cartas escritas por los profesores mexicanos Dres. Rayón, Andrade y Muñoz (D. Miguel), que actualmente residen en París, y concurrieron a la sesión que aquella célebre Académie Impériale tuvo la tarde del 29 de junio de 1869, cuando Mr. Jules Guérin defendió de nuevo la vacuna humana, aduciendo nuevas pruebas y haciendo uso principalmente de los mismos argumentos que emplearon sus defensores en México, los Sres. Muñoz (D. Luis), Domínguez, Rodríguez, Reyes (D. José María), Lavista, Menocal y Andrade; siendo de advertir, que el tan justamente afamado redactor de la Gaceta Médica de París hacía tiempo que había recibido de manos de nuestro compatriota el Sr. Andrade cuantos escritos sobre vacuna se habían publicado aquí. Como quiera que Mr. Guérin no haya tenido a bien, al menos hasta hoy, citar a los médicos mexicanos que defendieron a la vacuna humana, no obstante que se ha echado mano de sus argumentos y de sus trabajos, hemos creído de rigurosa justicia publicar este discurso, siquiera para que conste que en la Academia de Medicina de México fueron refutados, antes que en la de París o en alguna otra, los argumentos y los hechos en que quisieron apoyarse, tanto en Europa como en América, los defensores de la vacuna de terneras. Es una mera cuestión de prioridad, que defendemos, porque a ellos nos compulsan el honor nacional y otras causas particulares que sería ocioso referir»18,19.

Durante su gestión como presidente de la Academia, preocupado por la mortalidad infantil, publicó una convocatoria para un concurso denominado "¿Cuáles son las causas que originan las enfermedades que en la ciudad de México ocasionan la gran mortalidad de la primera infancia, y cuáles los remedios a propósito para combatirlas?", debiendo ser formuladas en preceptos claros y bajo la forma de cartilla, al alcance del vulgo. Se recibieron dos propuestas en sobre cerrado, una con el epígrafe "Cartilla que puede servir para remediar la mortalidad de la infancia en México" y la segunda como «Felix qui potuit rerum cognocer e causas"; sin embargo, el jurado calificador, integrado por los Dres. Agustín Reyes, Domingo Orvañanos, Demetrio Mejía y Luis E. Ruiz, consideraron que ninguna de las propuestas era acreedora al premio, por lo que se archivaron y no se publicaron $^{20}$.

\section{La Escuela Nacional de Ciegos}

La Escuela Nacional de Ciegos fue fundada en marzo de 1870 por el Sr. Ignacio Trigueros en unas aulas del antiguo Colegio de San Gregorio, proporcionadas por D. José M. Zayas. Posteriormente, en mayo de 1871, el gobierno de Benito Juárez cedió a la escuela parte del antiguo convento de La Enseñanza, reservado por entonces para prisión de Estado, la cual nunca pisó como prisionero el Dr. Domínguez gracias al ministro Lerdo de Tejada. La escuela fue dirigida por su fundador hasta el 22 de enero de 1877 y posteriormente estuvo don Antonio Martínez de Castro, hasta el 2 de agosto de 1878 en que pasó a la dirección el Dr. Manuel Domínguez, que por aquel tiempo era uno de los regidores de la corporación 
municipal y bajo cuyo gobierno alcanzó un grado de prosperidad que la puso al nivel de los establecimientos de su clase en Europa ${ }^{21,22}$. El Dr. Domínguez distribuía el trabajo de los alumnos de tal modo que, sin fatiga, podían desarrollar tanto su inteligencia como sus conocimientos en algún oficio y su aprendizaje musical. Ello permitió, entre otras cosas, que la orquesta de la escuela ofreciera conciertos en varias ciudades del país, como Orizaba y Toluca, donde eran muy aplaudidos. También se debe mencionar que, durante su administración, los alumnos recibieron numerosos diplomas y medallas por la presentación de sus trabajos en diversas exposiciones a las que concurrieron con sus trabajos, los cuales se podían apreciar en los muros de la escuela; ahí estaban los inapreciables documentos con que las juntas calificadoras de Ámsterdam, México, Veracruz, Toluca y Querétaro, entre otras, habían honrado a los alumnos por sus obras en pasamanería, esteras, tejidos de bejuco, cepillería, impresiones en puntos y letra realzada, encuadernación de libros, tejidos de aguja, etc. ${ }^{21,22}$. También debemos señalar que, guiado por su formación médica, el Dr. Domínguez se dio a la tarea de documentar las causas de la ceguera en los niños que llegaban a la escuela, siendo las más importantes viruela, oftalmía de recién nacidos, lesiones del fondo de ojo, queratitis ulcerosa (escrofulosa), estafiloma, consecuencia de operación desgraciada y quemadura de la cara, lo cual publicó en un folleto titulado Breve historia de la Escuela Nacional de Ciegos ${ }^{21}$.

\section{La Casa de Niños Expósitos (La Cuna)}

El Dr. Nicolás León menciona que el Dr. Domínguez le entregó un manuscrito inédito en el que narra la historia de la Casa de Expósitos, también conocida como La Cuna, quien lo publicó en su libro La Obstetricia en México en 1910. Ahí puede leerse lo siguiente: «Por disposición suprema, el 18 de enero de 1898 hice entrega de la dirección de la Escuela de Ciegos al Sr. Don Juan Ramírez de Arellano, pasando ese mismo día a la Casa de Expósitos para encargarme de su dirección, de la que me hizo entrega el Dr. Ángel Carpio. No sin cierta pena, debo confesarlo, me separé de un establecimiento a cuyo frente estuve 20 años, consagrándole todas mis energías en beneficio de la desdichada clase de sus asilados. Mi pena fue, sin embargo, atenuada en mucho por la consideración de que si aquel plantel, el de los ciegos, es altamente interesante por su nobilísimo objeto, no lo es menos el que recibe en su seno a los seres venidos al mundo sin que en éste los reciba el santo amor paterno, o por especiales circunstancias no puede ese natural afecto abrigarlos bajo su dulce sombra» 5 .

Hasta el 2 de octubre de 1905 estuvo el Dr. Domínguez al frente de tan benéfica casa, cuando por intrigas, según refiere el Dr. Rafael Carrillo en su trabajo titulado La cuna: su pasado, su presente y su porvenir, renunció al cargo de la dirección y en su lugar entró el Dr. Francisco de P. Carral ${ }^{23}$. Desde su llegada a La Cuna, el Dr. Manuel Domínguez se consagró con gran empeño a cumplir su cometido, llevando a cabo importantísimas reformas, principalmente en el cuidado de los asilados. A él se debe la formación de un «Reglamento de la Casa de Niños Expósitos", que incluía el de «Inspección de las nodrizas», en el cual mostró su preocupación por la alimentación y los cuidados médicos de los lactantes y las nodrizas que los alimentaban. Dicho reglamento fue aprobado por la Secretaría de Gobernación en 1898, y ahí podemos ver que existían tres grupos de niños asilados: los expósitos, niños abandonados, huérfanos de padre y madre, que no tenían deudo o persona que quisiera recogerlos, y eran los hijos legítimos de La Cuna; los amparados, niños que no podían ser sostenidos y educados por sus padres, a causa de la falta de recursos; y los pensionistas, niños que mediante pensión mensual eran llevados a la casa por sus padres o parientes. Ahí también se señala que se admitía a los niños desde su nacimiento hasta los 4 años de edad, cualquiera que fuera su sexo, pudiendo permanecer en la casa hasta la edad de 10 años los varones $y$ de 21 las niñas ${ }^{5}$.

El Capítulo I del citado reglamento se dedica a la atención de los niños, y en él queda asentado que la rectora debía recibir a los niños que se remitían en demanda de asilo, sea cual fuere la hora del día o de la noche, debiendo tomar nota de la edad de la criatura y las condiciones en que llegase. Habiendo comprendido el Dr. Domínguez las dificultades que había para identificar a los niños, creyó conveniente que, una vez presentados, el médico de la casa debía registrar metódicamente los datos biométricos y antropométricos, de tal manera que debía pesarlo, medirlo e inscribirlo en un libro especial bajo número progresivo, asentando la fecha en que se le recibía, su nombre (si tenía), el color de su piel, pelo y ojos, las señas particulares que en él hubiere y todos los datos que pudieran servir a la fácil identificación de la criatura ${ }^{1,5}$.

Según queda indicado en el reglamento, unos se quedarían en la casa y otros serían enviados al campo, al cuidado de nodrizas cuya salud y buena 
conducta serían acreditadas respectivamente por el médico y la autoridad política del lugar en que la mujer residiera. Todo niño enviado al campo que enfermase sería traído a la casa para su asistencia, y si por desgracia llegara muerto y la explicación de este hecho no fuese satisfactoria, el director debería consignar a la autoridad judicial competente el cadáver del niño, y a su nodriza, por si hubiere delito que penar. También serían devueltos a la casa los niños del campo en la edad del destete, estando obligadas las nodrizas del campo a venir a la casa cada 15 días con los niños que les fueron confiados, para que el director, acompañado del médico inspector de nodrizas, pasaran revista a las mujeres y los niños. Todo niño que, a juicio del médico inspector, no estuviera en buenas condiciones, recibiría una nodriza distinta o se quedaría en la casa, según lo que el facultativo creyere conveniente ${ }^{5}$. Estas disposiciones eran muy importantes, pues hasta ese entonces los niños eran llevados al campo, donde se entregaban a una mujer que hacía las veces de nodriza y alimentaba al niño sin previo reconocimiento médico, sin conocimiento de la calidad de su leche y que podría darle como alimento desde atoles hasta tortillas y frijoles, todo esto bajo la inspección inmediata de una mujer que, por su honradez nunca desmentida, era considerada como fiadora. Estos pobrecitos niños, durante su permanencia en el campo, hacían vida común con las nodrizas, vivían en las chozas más humildes, expuestos al rigor de todos los elementos y alimentados de la manera que mejor le placía a la nodriza, lo que daba lugar a que con frecuencia enfermaran y, lo que era más lamentable, que perdieran la vida ${ }^{23}$.

De conformidad con las disposiciones del Dr. Domínguez, los niños y las niñas asilados dentro de la casa se agrupaban en tres secciones: lactancia, de 2 a 5 años, y de más de 5 años; las dos primeras eran salas mixtas y la tercera tenía salas por sexos. Cada niño en lactancia tenía su nodriza, la que estaba bajo la vigilancia continua de una celadora y de la Sra. rectora, en lo relacionado a su conducta, a su aseo y al trato que dieran a la criatura que amamantaban. Mes a mes, el médico inspector debía practicar un reconocimiento de las nodrizas de la casa, a fin de cerciorarse de su salud y de la cantidad y calidad de su leche. Además, debía vigilar el crecimiento de los niños, sobre todo cuando se observaba que alguno de ellos no medraba. Los niños y las niñas de 2 a 5 años de edad estaban al cuidado de jóvenes hijas de la casa nombradas por el director Domínguez; había una por cada 10 criaturas, siendo todas dirigidas y amaestradas por una celadora, hija también de la casa. Por su parte, el director tenía entre sus obligaciones cuidar que los niños fuesen vacunados en tiempo oportuno, impedir que los empleados impusieran castigos a los niños que les causaran dolor físico o amenguaran su vergüenza, y autorizar el matrimonio de las jóvenes expósitas siempre que a su juicio el enlace fuese favorable para el porvenir de la joven ${ }^{5}$.

En la sala de cunas, la celadora de nodrizas debía cuidar de que estas trataran bien a los niños que amamantaban, que los bañaran cada tercer día, que los tuvieran constantemente aseados, lavando sus ropas cuantas veces fuese necesario, y que en las cunas no hubiese suciedad ni insectos. Por su parte, el médico de la casa tenía la obligación de visitarla todos los días en la mañana, aun cuando no hubiese enfermos, y de tarde o noche si así lo creyese necesario por haber algún enfermo grave ${ }^{5}$.

En el reglamento de la inspección de nodrizas se habla de un dispensario de nodrizas, el cual, también, fue aprobado por el Ministerio de Gobernación a finales de 1898, y que tenía como fin proporcionar nodrizas a las personas que las solicitaban; un verdadero beneficio público, ya que se había observado de tiempo atrás que las obtenidas al azar resultaban enfermas 0 con leche de mala calidad, cosas ambas de funestos resultados para los niños. El primer médico inspector fue el Dr. Miguel Márquez, quien tenía como obligación asistir diariamente a la oficina, recibir a todas las nodrizas que presentaban una solicitud de destino, reconocerlas y asentar en su libro el nombre de la nodriza, su edad, su domicilio, la fecha en que hizo su alumbramiento, la forma de los senos y del pezón, el estado de sus aparatos digestivo, circulatorio, respiratorio, nervioso y urogenital, signos de enfermedades previas o huellas de enfermedades generalizadas, y sobre todo el análisis de su leche, comprendiendo su color, abundancia, reacción, densidad, riqueza en mantequilla, azúcar, albuminoides, etc., así como los caracteres microscópicos de los elementos figurados. Se anotaba en un registro especial de las nodrizas el pueblo donde residía, las personas que abonaban su conducta y el niño que se le había confiado ${ }^{5}$. Al poco tiempo de haber llegado a La Cuna, el Dr. Domínguez solicitó a los jueces del Registro Civil que, al inscribir a los asilados hijos del establecimiento que no llevaban apellido se les pusiera el de Lorenzana, que fue el honorable fundador de esta casa de beneficencia. Poco después, el 9 de junio de 1899, el inspector de nodrizas propuso que se administrara en el establecimiento la vacuna 
bajo la inspección inmediata del Consejo Superior de Salubridad, lo cual fue aprobado el día 29 del mismo mes $^{5,23}$.

A causa de la falta de nodrizas, en noviembre de 1898 se propuso ensayar la lactancia artificial con leche de vaca mezclada con algunos cocimientos vegetales. Se realizó el experimento en 20 niños bajo la dirección de la rectora Sra. María B. Vda. de Escalante, pero la prueba no dio resultados satisfactorios. El 5 de octubre de 1899 entró a colaborar con el Dr. Domínguez un nuevo elemento, el Dr. Ricardo E. Cicero, quien ayudó al director en su labor de reorganizar la enfermería y el botiquín, llevar un libro adecuado del movimiento general de entradas y salidas de los asilados, anotando los datos antes señalados para su identificación, y adquiriendo en esa época una incubadora modelo Tarnier para salvar la vida de muchos niños prematuros 0 de debilidad congénita ${ }^{23}$.

Existe una anécdota de ese tiempo, mencionada por el Dr. Cicero, quien escribió: «El Dr. Domínguez se empeñó muchísimo en mejorar la atención que requerían los niños de la Casa Cuna, por lo que implantó un servicio médico tan completo como fue posible y se dotó de enfermeras y de botiquín. Sin embargo, se tenía en esa época una mala costumbre, que se procuró combatir inmediatamente: a los niños traviesos se les amenazaba con llamar al médico para que les recetara una purga, de modo que los asilados sentían temor por el médico. Se trabajó por desterrar ese temor tratando a los niños con cariño y haciéndoles comprender que el médico era su amigo. También se había observado que la mortalidad era elevada, sobre todo por enfermedades infectivas, especialmente el sarampión con sus terribles complicaciones respiratorias, por lo que se dispuso de un pabellón de aislamiento, pero a pesar de esta buena precaución no se pudo conjurar el peligro por el carácter especial de la enfermedad, que era contagiosa desde los primeros días»"24.

En 1904 renunció el Dr. Cicero a la plaza de médico del establecimiento, sustituyéndolo oficialmente el Dr. Rafael Carrillo el 16 de febrero de ese mismo año, quien colaboró con el Dr. Domínguez en las reformas de La Cuna, entre ellas la creación de una plaza de practicante y el establecimiento de unas ordenatas impresas donde se hacían constar todos aquellos datos indispensables para apreciar el estado de salud y enfermedad de los niños (peso, talla, alimentación, temperatura, etc.). Con el fin de buscar una solución al problema de la alimentación artificial, ya que continuaba la escasez de nodrizas, el Dr. Carrillo se propuso repetir el ensayo de la alimentación artificial, pues el de 1898 había sido insuficiente. En julio de 1904, animado por el Dr. José Terrés, clínico de gran renombre y uno de los principales propagandistas de la alimentación artificial, que practicaba con gran éxito en su clientela particular, y por el Dr. Aniceto Ortega, quien había implantado un sistema de leche esterilizada por autoclave, decidió llevar a cabo el experimento. Auxiliado por la rectora, Sra. Luz González Cosío de López, y por el personal de la Escuela de Enfermeras, se procedió al ensayo. La experiencia demostró que le leche esterilizada por la ebullición (procedimiento de Soxlet) y en autoclave, administrada exclusivamente en la alimentación de los niños menores de 1 año, era incapaz de sustituir el alimento natural, ya que la mayoría de los 30 bebés sometidos a la dieta experimental fallecieron de diarrea o inanición, incapaces de asimilar los alimentos. Esta falla de la alimentación artificial confirmó que la leche materna era superior para la alimentación y la sobrevida de los niños ${ }^{23-25}$. Durante su administración, de 1898 a 1905, el movimiento de criaturas fue de los más numerosos que tuvo La Cuna, ya que en ese período ingresaron 1598 niños, tan solo en 1903 ingresaron 454 niños, de los cuales 382 eran menores de 1 año de edad. Sin embargo, la mortalidad era elevada $(41.23 \%)^{23}$.

\section{El final de su fructífera vida}

El Dr. Manuel Justo Domínguez Quintanar (Fig. 1), varón virtuoso, médico ilustre y notable literato, sucumbió víctima de la peste blanca (tuberculosis) el 16 de marzo de 1910, a los casi 80 años de edad ${ }^{5}$. Su vida transcurrió con el desarrollo de la historia nacional: nació en los tiempos de la primera República Federal, se graduó de médico durante la dictadura de López de Santa Anna, desarrolló su actividad asistencial y política durante la reforma, la invasión francesa, el segundo imperio mexicano, la república restaurada y, por supuesto, el porfiriato, falleciendo unos meses antes del estallido revolucionario que cambiaría por completo el panorama político y social de México.

\section{Corolario: la puericultura y la pediatría técnica}

A pesar del conocimiento sobre las enfermedades infantiles, a finales del siglo XIX el oficio del arte se llevaba a cabo en condiciones de ensayo y dentro 
de la oscuridad de los fenómenos de la infancia. Sin embargo, a decir del Dr. Rafael Carrillo, la labor del Dr. Domínguez fue altamente altruista e intensa, y a él se deben los primeros pasos para fundar una escuela de puericultura racional, situación reconocida y fortalecida por el maestro Dr. Alfonso G. Alarcón, quien señala que fue su espíritu sagaz lo que le permitió crear en 1900 la pediatría técnica en Méxi$\mathrm{Co}^{2,23}$. El papel de la Casa de Expósitos en la regulación de las nodrizas y sus innovaciones en la alimentación infantil pusieron los cimientos de nuestra puericultura nacional y establecieron un prototipo para la salud y los programas de bienestar públicos, que surgieron después de la revolución. Los médicos que administraban los programas de alimentación infantil en la Casa de Expósitos (La Cuna) emergieron después de la guerra como los líderes de la puericultura mexicana. La pérdida de población durante la revolución llevó al proyecto de reducción de la mortalidad como una prioridad nacional. Los programas de salud pública iniciados a principios de 1920 reflejaron la influencia de la puericultura en el bienestar de los niños mexicanos. La puericultura ofreció entonces un abordaje científico para la salud y el desarrollo del niño desde la concepción hasta la pubertad, estrechamente ligados con la atención a la salud de la madre, al ambiente higiénico en el hogar y a los lugares donde el niño pasaba parte de su tiempo ${ }^{25,26}$.

\section{Bibliografía}

1. Alarcón AG. La aportación de los médicos mexicanos a la pediatría. Gac Med Mex. 1944;74:323-43.

2. León N. La obstetricia en México. México: Tip. de la Vda. de F. Díaz de León, Sucrs.; 1910.

3. Anónimo. Biografía del autor. En: Domínguez M. Obras (leyendas históricas). México: Imp. de V. Aguepos; 1909. p. V-XVI.

4. Domínguez M. Discurso pronunciado por el Dr. Manuel Domínguez en la ceremonia de la inauguración del monumento al Dr. Manuel Carmona y Valle. En: Domínguez M. Obras (leyendas históricas). México: Imp. de V. Aguepos; 1909. p. 421-44.

5. López de Santa-Anna A. Decreto del gobierno. Plan general de estudios de la República mexicana. En: Dublan M, Lozano M, editores. Legislación mexicana o edición completa de las disposiciones legislativa expedidas desde la Independencia de la República. Tomo IV. México: Imprenta del Comercio, a cargo de Dublan y Lozano, hijos; 1876. p. 514-23.

6. Ocaranza F. Historia de la medicina en México. París: Drager; 1934. p. 155-7.

7. Cano-Sordo V. De la Luisiana a la Nueva España. La historia de Juan Bernardo Domínguez y Gálvez (1783-1847). México, D.F.: Impresora Múltiple; 1999

8. Ratz K, Gómez-Tepexicuapan A. Los viajes de Maximiliano en México (1864-1867). México, D.F.: CONACULTA; 2012.

9. Anónimo. Anuario de las Ordenes Imperiales. México: Imprenta de J. M. Lara; 1865. p. 13.

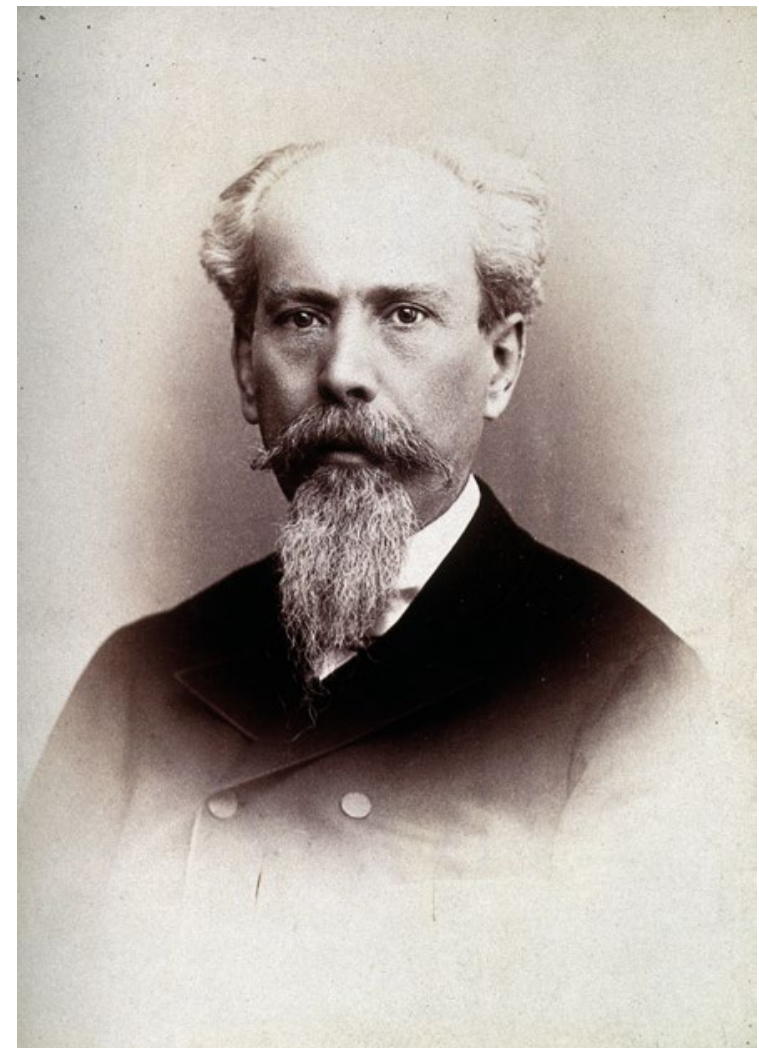

Figura 1. Dr. Manuel Justo Domínguez Quintanar (fotografía de Cruces y Cía., Colección Wellcome).

10. Fajardo-Ortiz G. Una investigación acerca del historial médico durante el sitio de Querétaro, 1867. Gac Med Mex. 1997;133:35-9.

11. Acuña M. Obras. Barcelona: Tip. Casa Editorial Sopena; 1873. p. 109.

12. Caffarel-Peralta R. El verdadero Manuel Acuña. México: UNAM; 1999.

13. León N. Biblioteca Botánico-Mexicana. México: Oficina Tip. de la Secretaría de Fomento; 1895. p. 109.

14. El Heraldo. El Sr. Dr. D. Manuel Domínguez. Gac Med Mex. 1910;5:I-IV.

15. Domínguez M. Carta abierta a mis electores. De México a San Juan del Río. 28 de agosto de 1878.

16. Flores FA. Historia de la Medicina en México, desde la época de los indios hasta la presente. Tomo III. México: Oficina Tip. de la Oficina de Fomento; 1888.

17. Cárdenas-de la Peña E. Médicos mexicanos. El doctor Manuel Domínguez, ilustre médico queretano. Bol Mex His Fil Med. 2000;3:33-9.

18. Los redactores. A nuestros suscriptores. Gac Med Mex. 1869;4:255-6.

19. Domínguez M. ¿La vacuna humana puede ser vehículo para la sífilis? Gac Med Mex. 1869;4:256-67, 271-8.

20. Cordero M. Sesión del 27 de octubre de 1887. Acta Núm. 5, aprobada el 9 de noviembre. Presidencia del Sr. Dr. Bandera. Gac Med Mex. 1887;22:531-3.

21. Domínguez M. Breve historia de la Escuela Nacional de Ciegos. México: Oficina Tip. de la Secretaría de Fomento; 1889.

22. Rivera-Cambas M. México pintoresco, artístico y monumental. Tomo segundo. Escuela Nacional de Ciegos. México: Imprenta de la Reforma; 1882. p. $120-6$.

23. Carrillo R. La Cuna; su pasado, su presente, su porvenir. Gac Med Mex. 1915;10:320-44.

24. Cicero R. Acta número 13. La Casa de Cuna. Gac Med Mex. 1915; 10:565-6.

25. Carrillo R. Gestación: la puericultura en México. Rev Mex Pediatr. 2005; 72:94-6.

26. Blum AS. Domestic economies. Family, work, and wellfare in Mexico City, 1884-1943. Nebraska: University of Nebraska Press; 2009. p. 71-102. 